\title{
TEATRO COMUNITARIO Y TESTIMONIO EN LA ESCENA ESPAÑOLA FUEGOS (2017), DE LOLA BLASCO Y LA NAVE
}

\section{LUISA GARCÍA-MANSO}

Universiteit Utrecht

m.l.garcia-manso@uu.nl

RESUMEN: En la actualidad, se observa un creciente interés por el teatro comunitario en España. Entre las modalidades de teatro comunitario, se puede distinguir entre propuestas escénicas dirigidas a, creadas por o interpretadas por una comunidad. Estos proyectos tienen la peculiaridad de estimular la participación de personas que no siempre están familiarizadas con el teatro, lo que tiene un efecto positivo en la promoción de su agencia cultural. En este marco, destaca la iniciativa de La Nave del Teatro Calderón de Valladolid, que ha contribuido a desarrollar el talento creativo de sus participantes, al mismo tiempo que ha atraído nuevos públicos al teatro. Cada año, desde 2014, más de cincuenta jóvenes de entre 16 y 26 años participan en el programa. Los llamados "Navegantes", dirigidos por Nina Reglero y Carlos Nuevo, elaboran una propuesta escénica multidisciplinar sobre un tema concreto. Este ensayo analiza el uso del testimonio, el documento y los nuevos lenguajes expresivos — como el hashtag - en Fuegos (2017), obra dramática sobre los éxodos con texto dramático de Lola Blasco, quien tuvo en cuenta las ideas de los Navegantes. Durante el proceso creativo, contaron con la colaboración de la estudiante refugiada Marah Rayan. En el artículo se plantea que propuestas de teatro comunitario como Fuegos ofrecen distintas formas de testimonio. Por un lado, se halla el testimonio textual, basado en la experiencia vital de Marah Rayan, que ella misma interpreta sobre el escenario, contribuyendo a su autorrepresentación. Por otro lado, la mera presencia física de miembros de la comunidad en escena puede considerarse como un testimonio corporeizado.

PALABRAS CLAVE: teatro comunitario, comunidad, testimonio, documento, exilio, refugiados. 


\section{COMMUNITY THEATER AND TESTIMONY ON THE SPANISH STAGE: Lola Blasco's Fuegos (2017), and La Nave}

ABSTRACT: Currently there is a growing interest in community theater in Spain Among the modalities of community theater, it is possible to distinguish proposals of scenes addressed to, created by, and performed by a community. These projects encourage the participation of persons who are not necessarily familiar with theater, which has a positive effect on the promotion of their cultural agency. In this context, the initiative of La Nave of the Calderón Theater of Valladolid stands out. La Nave has succeeded in both fostering the creative talent of its participants and in attracting new audiences to the theater. Every year since 2014, more than fifty young people between 16 and 26 years old participate in the program. The so-called Navegantes, led by Nina Reglero and Carlos Nuevo, develop proposals for a multidisciplinary stage on specific topics. This article analyzes the use of testimony, documents, and new expressive languages -such as the hashtag-in Fuegos [Fires] (2017), a play about instances of exodus written by Spanish playwright Lola Blasco, who took into account the ideas of the Navegantes. During the creative process, Blasco and the Navegantes counted on the collaboration of the refugee student Marah Rayan. This article argues that community theater proposals, such as Fuegos, represent different forms of testimony. On the one hand, there is a textual testimony based on Marah Rayan's life experience, which she performs on stage as part of her self-representation. On the other, the sole physical presence of community members on stage can be considered a form of embodied testimony.

KEY WORDS: community theatre, testimony, document, exile, refugees.

\section{Aproximación al teatro comunitario: cuestiones terminológi- cas y tipología}

$\mathrm{C}^{\mathrm{n}}$ la actualidad es posible observar en España un creciente interés en Ctorno a propuestas escénicas de teatro aplicado y teatro comunitario, en las que determinadas comunidades o grupos participan como intérpretes e, incluso, como creadores de montajes escénicos. ${ }^{1}$ Aunque por el

${ }^{1}$ Véase el artículo de Ojeda publicado en El Cultural, quien reseña varias propuestas escénicas recientes en las que se observa que "en España coge ritmo el teatro comunitario, aplicado, inclusivo...".

UNED. REI, 7 (2019), pp. 209-236 momento no existen muchos estudios sobre estas formas artísticas en España, dichas modalidades cuentan con una tradición asentada en otros países, hasta el punto de que existen festivales internacionales, programas de máster, revistas científicas y colecciones en editoriales de prestigio sobre las mismas. ${ }^{2}$ El propósito de este ensayo es indagar en el papel que juega el testimonio en las propuestas de teatro comunitario que incorporan en sus procesos creativos materiales generados por la comunidad involucrada en el proyecto escénico. Dada la gran diversidad de las propuestas escénicas comunitarias, me centraré en el análisis del montaje de Fuegos, llevado a cabo dentro del proyecto "La Nave" del Teatro Calderón de Valladolid, con dirección de Nina Reglero y textos de Lola Blasco y los Navegantes. ${ }^{3}$

Definir qué es teatro aplicado y qué es teatro comunitario no carece de complicación, puesto que bajo ambos términos se engloban propuestas creativas y escénicas muy variadas e incluso los propios conceptos están sujetos al escrutinio académico. En ocasiones 'teatro aplicado' y 'teatro comunitario' se utilizan como sinónimos, pero no lo son. De hecho, el teatro comunitario suele concebirse como una de las posibles modalidades del teatro aplicado, que funciona como hiperónimo o término paraguas, abarcando así fórmulas creativas tan diversas como el teatro del oprimido, el teatro para cambio social, el teatro para el desarrollo, la performance participativa, el teatro carcelario, ${ }^{4}$ el teatro de educación para la salud, el

2 Por ejemplo, el International Community Arts Festival que tiene lugar en Rotterdam cada tres años; el programa de Master of Arts en "Applied Theatre and Intervention" de la University of Leeds o el Master of Arts en "Applied Anthropology and Community Arts" de Goldsmiths, University of London; la revista internacional Research in Drama Education: The Journal of Applied Theatre and Performance; o la colección de estudios en "Community Theatre" de la editorial Routledge y la de "Applied theatre" de la editorial Bloomsbury.

${ }^{3}$ Nombre con el que se identifican los participantes del proyecto "La Nave".

${ }^{4}$ En el ámbito español destacan proyectos escénicos como el Teatro-Escuela de El Dueso, dirigido por Cipriano Rivas Cherif durante su condena en el Penal del Dueso entre 1942 y 1945; ya en la época democrática, Teatro Yeses, dirigido por Elena Cánovas, funcionaria de Instituciones Penitenciarias, desde 1985 en diversas cárceles; y, más recientemente, la compañía teatroDENTRO, residente en el Centro Penitenciario de Quatre Camins (Barcelona, 2005-2014) y auspiciada por transFORMAS, entidad de artes escénicas y transformación, fundada por Eva García.

UNED. REI, 7 (2019), pp. 209-236

ISSN 2340-9029 
teatro para la resolución de conflictos o la reconciliación, el teatro para el recuerdo, el teatro museo, el psicodrama y el teatro playback, entre otros (Prentki y Preston, 2009: 9; Motos, 2015: 46-65). Prentki y Preston sintetizan en la siguiente definición algunos denominadores comunes de esta diversidad de prácticas escénicas:

'Applied theatre' has emerged in recent years as a term describing a broad set of theatrical practices and creative processes that take participants and audiences beyond the scope of conventional, mainstream theatre into the realm of a theatre that is responsive to ordinary people and their stories, local settings and priorities. The work often, but not always, happens in informal spaces, in non-theatre venues in a variety of geographical and social settings: schools, day centres, the street, prisons, village halls, an estate or any other location that might be specific or relevant to the interests of a community. Applied theatre usually works in contexts where the work created and performed has a specific resonance with its participants and its audiences and often, to different degrees, involves them in it. (Prentki/ Preston, 2009: 9)

En lo que respecta al uso de "teatro aplicado" y "teatro comunitario" como conceptos intercambiables, Eugene van Erven señala que algunos autores prefieren hablar de teatro "aplicado" por considerarlo un término más neutral, que evade las implicaciones semánticas e ideológicas del uso de la noción de 'comunidad' (2015a: 407). En este sentido, hablar de comunidad implica asumir la existencia de algo que une a las personas en su diversidad, que les permite reconocerse como miembros, bien sea por su cercanía física o vecindad o porque comparten otros elementos identitarios. Por este motivo, el teatro comunitario pretende también democratizar la cultura y hacerla accesible a personas que suelen mantenerse al margen del teatro, tanto desde la perspectiva de la creación como de la recepción. Tras analizar un conjunto de proyectos escénicos realizados en varios lugares del mundo, Erven concluye que en todos ellos es posible observar "the central aim of providing the members of socially, culturally, ethnically, economically, sexually, culturally, or otherwise peripheral 'communities' with the artistic means to collectively and democratically express their concerns and passions in their own, albeit aesthetically mediated, voices" (2000: 255). Entre las características esenciales del teatro comunitario destaca, por tanto, la intención política de transformar la sociedad:

[...] se confía en las posibilidades formativas del arte y la creatividad, en su capacidad para generar una transformación cultural y social -especialmente a través del aprendizaje bidireccional, en este caso artista-comunidad, comunidad-artista- $y$, en un sentido más amplio, en la capacidad de la educación y la cultura para cambiar la vida de los colectivos y los individuos. (Erven, 2015b: 55)

El teatro comunitario tiene, por consiguiente, el objetivo de canalizar y catalizar la expresión artística de los miembros de una comunidad. Dichos miembros participan activamente en el proceso creativo de la propuesta escénica, para la que cuentan con la mediación de un artista o "facilitador". Se trata de un teatro de, por y para la comunidad (Geer, 1993; cf. Cohen-Cruz, 2005: 2). En este sentido, se pueden identificar tres aproximaciones al teatro comunitario en función del papel o grado de participación desempeñado por los miembros de la comunidad en cuestión (Prentki y Preston, 2009: 10).

1) Teatro para la comunidad: se trata de proyectos escénicos dirigidos a comunidades concretas. En esta modalidad, la comunidad asume el papel de público y, normalmente, la idoneidad del montaje parte de una investigación previa y tiene un objetivo social o político. Como ejemplo, cabe señalar Antígona (2000), montaje del Grupo Cultural Yuyachkani con texto de José Watanabe, con la que se plantea una versión libre del drama de Sófocles centrada en la figura de Ismene. Esta obra fue llevada a escena en zonas rurales de Perú con el fin de apoyar la labor de la Comisión de Verdad y Reconciliación y animar a posibles testigos a dar testimonio sobre el terrorismo y la represión militar (Lambright, 2013).

2) Teatro realizado con la comunidad: cuando se desarrollan talleres teatrales y procesos creativos con una comunidad, pero estos no se dirigen necesariamente a la representación pública o esta es llevada a cabo por actores profesionales. Para ilustrar esta modalidad se pueden ci- 
tar ejemplos como Kalimat (Palabras) (2016), una propuesta escénica con dramaturgia y dirección de Helena Tornero, en la que intérpretes profesionales presentan una lectura dramatizada de testimonios reales recabados en el campo de refugiados de Nea Kavala, en el norte de Grecia, donde la compañía impartió talleres de teatro dentro del proyecto Paramythádes ("contadores de historias"). Otro ejemplo se halla en la exitosa Fiesta, fiesta, fiesta (2017), de Lucía Miranda y su compañía The Cross Border Project. Se trata de una propuesta de teatro verbatim ${ }^{5}$ centrada en la diversidad cultural, en la que un elenco de intérpretes profesionales corporeiza testimonios reales recabados en entrevistas a profesores, estudiantes, padres y personal no docente de un instituto de educación secundaria, con los que además realizaron talleres de teatro. En ambos casos el papel de las dramaturgas y directoras de escena consistió en organizar y dar forma dramática al material documental propiciado por los miembros de la comunidad, que podemos considerar, en ese sentido, como informantes.

3) Teatro realizado por la comunidad, en el que la comunidad es intérprete y protagonista del proceso escénico y del resultado final. Esta última modalidad coincidiría con lo que Cohen-Cruz denomina "community-based theatre" (teatro basado en la comunidad), haciendo hincapié en la relación indisociable entre el hecho escénico y la comunidad que lo protagoniza. En esta modalidad se puede catalogar la obra de teatro que será fruto de análisis más detallado en el presente ensayo, Fuegos, realizada en el marco del proyecto cultural de La Nave del Teatro Calderón de Valladolid, con jóvenes de entre 16 y 26 años.

Según Cohen-Cruz, los objetivos de un montaje de teatro basado en la comunidad deben decidirse de manera colectiva por los propios participantes, a diferencia de otras fórmulas que se corresponden con el drama aplicado, como el psicodrama o el teatro en la educación (theatrein-education), en los que los participantes cuentan con cierto grado de agencia, pero los objetivos del montaje no están tan abiertos a discusión $\mathrm{y}$ el profesor o terapeuta cuenta con mayor autoridad que el facilitador

${ }^{5}$ Véase Abuín González (2016) para más información sobre las técnicas del teatro verbatim y su conexión con algunas muestras emblemáticas de teatro comunitario fuera de España.

UNED. REI, 7 (2019), pp. 209-236
(2005: 6). Asimismo, considera que no todo el teatro comunitario cumple con este requisito: "community theater is enacted by people who neither generate the material, shape it, work with professional guidance, nor apply it beyond an entertainment frame" (2005: 7).

Además de las compañías y propuestas mencionadas más arriba, cabe destacar proyectos tan emblemáticos como la Fundación Psico Ballet Maite León, formada en 1986 para la formación escénica integral de personas con diversidad funcional; el de la directora y autora teatral Paloma Pedrero, al frente de la ONG Caídos del cielo, que trabaja con personas sin hogar y otros grupos en riesgo de exclusión social, como los refugiados e inmigrantes en situación irregular; la compañía TransFORMAS - Artes escénicas y Transformación -, creada en 2004 en Barcelona por Eva García y otros profesionales del teatro que trabajan con técnicas del Teatro del Oprimido y el teatro foro de Augusto Boal; o el Colectivo Lisarco, asociación de profesionales de diferentes disciplinas artísticas, formada en 2006, que apuesta por la diversidad y la inclusión. ${ }^{6}$

\section{2. "Y los jóvenes fueron al teatro": el proyecto de teatro comuni- tario de La Nave}

La Nave es un programa artístico multidisciplinar para jóvenes del Teatro Calderón de Valladolid iniciado en octubre de 2014 ("El proyecto", 2014). Hasta el momento, cuenta con cuatro ediciones. Cada año se seleccionan jóvenes de entre 16 y 26 años interesados en explorar sus capacidades y habilidades artísticas en ámbitos como la escritura, los lenguajes audiovisuales, el diseño, la pintura, la composición musical, el canto, la

\footnotetext{
${ }^{6}$ Véase García-Manso (2018) para una profundización en otros proyectos escénicos concretos como Harragas (2006), de Marina Bollaín, y La casa de Bernarda Alba (2009), en la versión dirigida por Pepa Gamboa con un grupo de mujeres de etnia gitana del poblado chabolista de El Vacie.

"Y los jóvenes fueron al teatro" es el titular de un artículo de Raquel Vidales sobre La Nave y Fuegos publicado en El País.
} 
danza y la interpretación. ${ }^{8}$ El objetivo del programa es doble; por una parte, pretende promocionar el talento artístico y creador de sus participantes y, por otra, generar nuevos públicos atrayendo a los jóvenes al teatro y situándolos en un contexto privilegiado para conocer la programación cultural de su ciudad y asistir a ensayos, espectáculos, clases y talleres:

La Nave es un espacio de encuentro e integración de las artes escénicas con otras disciplinas artísticas, donde catalizar las inquietudes expresivas. Un lugar donde proponer alternativas a los modos convencionales del pensamiento y acción escénica... Un laboratorio en el que es posible trabajar con profesionales que coordinan los procesos de creación en sus diferentes etapas, poniendo a disposición el entorno físico, técnico y profesional del Teatro Calderón, en Valladolid. (“Green-Eyed Monster”, 2016)

Los participantes del proyecto, autodenominados "Navegantes", trabajan en la elaboración de propuestas artísticas en sus diversas disciplinas en torno a un tema concreto. El proceso creativo culmina con la representación pública de una obra teatral. Los Navegantes son apoyados a lo largo del proceso por un grupo de artistas profesionales. Los coordinadores artísticos son Nina Reglero (dirección escénica) y Carlos Nuevo (espacio escénico y coordinación de audiovisuales y diseño). ${ }^{9}$ Paulatinamente, el proyecto ha ido incorporando a más profesionales de las artes escénicas, como la figurinista Ana Garay y los coreógrafos Manuela Barrero (2015 hasta el presente) y Chevy Muraday (2015-2016). En las dos últimas ediciones, además, han contado con la colaboración de una dramaturga para recabar los materiales e ideas de los Navegantes y componer un texto dramático para la puesta en escena. Hasta el momento las autoras involucradas han sido Lola Blasco y María Velasco.

En una charla impartida en los Encuentros Te Veo 2017, Nina Reglero definía el trabajo de La Nave como un proceso investigador. En lo

${ }^{8}$ En la primera edición de 2014 se seleccionaron 45 jóvenes (“El proyecto", 2014), mientras que en 2017 Nina Reglero hablaba de hasta 80 participantes (TEVEO Asociación).

${ }^{9}$ Ambos integrantes de la compañía Rayuela Producciones Teatrales. que respecta al proceso creativo, explicaba que son los propios Navegantes quienes "de forma gradual, [...] generan sus contenidos, ellos generan su música, generan sus textos, generan sus coreografías, los audiovisuales, y a partir de ahí entramos los profesionales para darles un soporte profesional y hemos llegado a hacer montajes profesionales, incluso con actores profesionales mezclados con los chicos, pero son ellos mismos los que están en escena” (TEVEO Asociación, 2017: 01:00-01:24). Así pues, se puede observar que la metodología de trabajo que utilizan sigue las pautas de un teatro comunitario realizado por la propia comunidad -o, en la conceptualización de Cohen-Cruz, basado en la comunidad-, en la que los artistas profesionales adoptan el rol de facilitadores.

Hasta el momento se han presentado los siguientes espectáculos al público: Palabras cruzadas (2015), Metamorfosis (2015), Green-Eyed Monster (2016), Fuegos (2017), Cenizas (2017) y Ágora (2018). ${ }^{10}$ Palabras cruzadas consistió en una escenificación de textos creados por los Navegantes centrados en la influencia de las redes sociales sobre los comportamientos y la forma de relacionarse de los jóvenes. Con Metamorfosis plantearon una lectura escénica transversal de La metamorfosis de Kafka, tomando como hilo conductor "los permanentes cambios a los que se enfrenta la juventud desde la primera adolescencia hasta la estabilidad de su desarrollo como adulto" ("Metamorfosis", 2015). En Green-Eyed Monster indagaron en el tema de la violencia de género tomando como punto de partida el Otelo de Shakespeare. Para este montaje, contaron con cinco actores profesionales - Javier Prieto, Alba Pérez, Álvaro Vázquez, María Prado y José Francisco Ramos-, quienes interpretaron a los personajes principales de la tragedia de Shakespeare ("Green-Eyed Monster", 2016). En Fuegos investigaron sobre los éxodos de ayer y hoy y contaron con el apoyo dramatúrgico de Lola Blasco, una autora que desde sus primeros textos le ha prestado una especial atención a esta temática. Aquellos trabajos que no fueron incorporados en el montaje final de Fuegos se mostraron en Cenizas. Por último, en Ágora trabajaron sobre la responsabilidad co-

${ }^{10}$ Tras la finalización de este artículo se anunció el estreno de Morlockland (LAVALaboratorio de las Artes de Valladolid, 14-05-2019), montaje que Los Navegantes han preparado en la temporada 2018-2019.

UNED. REI, 7 (2019), pp. 209-236

ISSN 2340-9029 
munitaria en la era de internet y contaron con la autora María Velasco para la creación del texto final.

Tras el éxito del programa, en 2017 se puso en marcha La Nave senior, en este caso dirigida a "Navegantes" mayores de 65 años con la finalidad de "compartir un tiempo común de encuentro e integración a través de las artes escénicas con otras expresiones artísticas, un lugar donde fomentar la participación, las relaciones interpersonales y las inquietudes artísticas" ("La Nave senior"). Los coordinadores artísticos de este proyecto son Félix Fradejas y Marta Ruiz de Viñaspre, ambos procedentes de la compañía Ghetto 13/26. Otro proyecto hermano es La Nave del Teatro Sánchez Aguilar de Guayaquil, en Ecuador. Nina Reglero y Carlos Nuevo trabajaron allí en agosto de 2018 con la misma metodología que en Valladolid. Con esta iniciativa, se pretende fomentar el intercambio artístico y la interactuación entre los jóvenes de ambos países ("La Nave", 2018)

Entre las iniciativas afines generadas en otros teatros públicos destacan dos programas recientes del Conde Duque de Madrid. En junio de 2018 dio comienzo el laboratorio "Aves Migratorias de Madrid", dirigido a jóvenes de entre 18 y 25 años interesados en la creación escénica y con cualquier tipo de formación. Acompañaron a los 16 jóvenes seleccionados en su proceso creativo los artistas de Sleepwalk Collective. El laboratorio cuenta con un enfoque transdisciplinar que integra teatro, danza, performance y cine ("Aves Migratorias"). También en 2018 se puso en marcha "Generación Global", un proyecto de teatro comunitario dirigido a jóvenes de "entre 14 y 18 años de distintos orígenes, con especial atención hacia personas migrantes, refugiadas y refugiados". Las mediadoras son Lucía Miranda, Marina Santo y Belén Santa-Olalla y el coordinador es Nacho Bilbao ("Generación Global").

\section{Fuegos, de Lola Blasco y los Navegantes: la búsqueda de un lenguaje común, las formas del testimonio y el documento}

El montaje de Fuegos se estrenó el 27 de mayo de 2017 en la Cúpula del Milenio (Valladolid), durante el Festival Internacional de Teatro y
Artes de Calle (TAC). ${ }^{11}$ Posteriormente sería llevado a escena en el Teatro Calderón, para lo cual tuvo que adaptarse al nuevo espacio, más reducido y con la estructura convencional a la italiana. El texto dramático de Lola Blasco, publicado en 2017, lleva el subtítulo El hígado de Prometeo y se estructura en tres capítulos compuestos, respectivamente, de cinco, tres y una escena. La redacción del texto se llevó a cabo al mismo tiempo en que Los Navegantes trabajaban en sus propuestas. En la nota inicial al texto dramático - "Aviso a los navegantes" - , la autora aclara que se trata de una obra escrita en diálogo con los participantes de La Nave y destaca en concreto "el trabajo de Noelia Toribio, que inspiró la escena 'Europa se sienta de Espaldas' y de Lorenzo Asensio cuyo poema 'a (dolescente)' ha sido publicado íntegro con el texto" (Blasco, 2017: 5). Por último, Blasco menciona el testimonio de Marah Rayan, colaboradora especial de La Nave que transmitió a los participantes y a la autora su experiencia vital como refugiada palestina en Siria durante el conflicto. Rayan, además, participó en la puesta en escena dando voz a su propio testimonio, que conforma la última escena de la obra.

La Tesis Fin de Máster y el documental Una travesía en La Nave de Sandra García Pindado (2017a, 2017b), una de las Navegantes, ofrecen información acerca del proceso creativo de Fuegos. Todos los profesionales mencionados más arriba - Nina Reglero, Carlos Nuevo, Manuela Barrero, Ana Garay y Lola Blasco- participaron en sesiones de trabajo con los Navegantes, organizadas generalmente en grupos más pequeños, encargados de ir desarrollando distintas propuestas artísticas. En la parte final del proceso contaron también con la colaboración de Marah Rayan y de algunos de los integrantes de la Nave Senior, que participarían también en el montaje, declamando los cuentos de la escena II del capítulo II ("Cuentos para ancianos, cuentos como refugios"). En la puesta en escena se combinaron las distintas artes exploradas en el proyecto: música en directo con composiciones de los Navegantes, coreografía y movimiento escénico, dibujo, fotografía, vestuario, utilería, uso de recursos audiovisuales, etc. Durante el espectáculo, todos los Navegantes permanecían en escena.

${ }^{11}$ En el marco de dicho festival el espectáculo fue galardonado con el Premio Estación Norte TAC 2017.

UNED. REI, 7 (2019), pp. 209-236

ISSN 2340-9029 
La participación de Lola Blasco en el proyecto contribuyó, sin duda, a darle una mayor visibilidad al montaje, dada la destacada proyección de la autora en la escena española contemporánea. ${ }^{12} \mathrm{El}$ tema del éxodo se halla muy presente en su obra. Alusiones a diferentes tipos de exilios, migraciones, deportaciones, desplazamientos y encuentros con el Otro aparecen en textos como Los hijos de las nubes (2012), En defensa (Un concierto de despedida) (2014), María Zambrano (2014), La confesión del Quijote (2015), ;Teme a tu vecino como a ti mismo! (2016), La armonía del silencio (2016) y Siglo mío, bestia mía (2017). El texto de Fuegos ha sido publicado, de hecho, junto con En defensa (Un concierto de despedida), una obra en la que la reflexión sobre el exilio ocupa un lugar central (Blasco, 2017). Me interesa aludir brevemente a este texto, ${ }^{13}$ dado que en él se vierten reflexiones de la autora sobre su poética. En defensa fue presentada como lectura dramatizada en 2011 en la Sala Cuarta Pared y parte del texto-Un concierto de despedida- se publicó en 2012 en la revista Acotaciones. La obra se enmarca en plena crisis económica, en la época del Movimiento $15 \mathrm{M}$ y de la emigración de jóvenes españoles al extranjero en busca de empleo. Esta realidad acuciante dialoga con una serie de antecedentes históricos y literarios, como la Odisea de Homero, la elección de Sócrates - tomar cicuta o exiliarse-, las Tristes de Ovidio y el

${ }^{12}$ Lola Blasco (Alicante, 1983), autora formada en la RESAD y galardonada en 2016 con el Premio Nacional de Literatura Dramática, disfruta en la actualidad de una beca en el Departamento de Humanidades de la Universidad Carlos III de Madrid, donde realizó un Máster en Humanidades. En 2009, Blasco funda Abiosis Teatro y estrena su primera obra, Foto finis. Desde entonces, ha publicado y estrenado numerosas obras dramáticas, algunas de las cuales han sido dirigidas e interpretadas por ella misma, como la reciente Música y mal (El Pavón Teatro Kamikaze, Madrid, 23-05-2018). Su participación en prestigiosos programas de promoción de las artes escénicas ha contribuido a visibilizar su obra: Espacio Teatro Contemporáneo (ETC) de la Sala Cuarta Pared, la Muestra de Teatro Español de Autores Contemporáneos, el Programa de Desarrollo de Dramaturgias Actuales del INAEM y Escritos en la Escena del Centro Dramático Nacional. Para un acercamiento a las características de la última generación de autores y autoras dramáticos en España pueden consultarse los estudios de Checa Puerta (2012b), Pérez Rasilla (2012), Gutiérrez Carbajo (2014) y el volumen editado por Romera Castillo (2014), entre otros.

${ }^{13}$ Un análisis más pormenorizado de En defensa se encuentra en Checa Puerta (2017) y Jódar Peinado (2017). exilio republicano español de 1939. Al mismo tiempo, En defensa -el título completo de la obra en su primera versión era: En defensa de un teatro político revolucionario-, constituía toda una declaración de intenciones por parte de Blasco. En el prólogo, titulado "Diálogo para un teatro político revolucionario", la autora presenta un diálogo socrático ficticio entre Lola Blasco y Alfonso Sastre. Partiendo del Diálogo para un teatro vertebral (2002) de Sastre, Blasco defiende un teatro que se compromete con la realidad trascendiéndola a través del uso del mito y de la metáfora. El personaje de Alfonso Sastre, tanto en Diálogo para un teatro vertebral como en En defensa, afirma: "Las metáforas nos ayudan, mediante la autonomía del nivel poético al desvelamiento de la realidad, a ese desvelamiento... que es la verdad" (Sastre, 2002: 10; Blasco, 2017: 74). Es posible leer el teatro de Blasco a la luz de estas palabras, un teatro que se compromete con la realidad y la refleja a través de una indagación en cuestiones transcendentales, irresueltas -el éxodo, el mal, la responsabilidad, la culpa...-, construidas sobre mitos, arquetipos, símbolos y otras imágenes y referencias a la tradición cultural, el cine y la música. Esa tradición cultural se convierte en una forma de "lenguaje común" que le permite proponer al público un teatro político que se posiciona ante la realidad (Blasco, 2016: 44):

L.B.: Estoy buscando un tema común.

A.S.: ¿Un tema común?

L.B.: Un lenguaje común, por ejemplo entre usted y yo. Algo de

lo que podamos hablar y nos entendamos. Una vía de acceso para el entendimiento entre usted y yo.

A.S.: ¿Para que nos entendamos?

L.B.: No solo usted y yo. Busco una imagen. Como la de Ulises. Una imagen que puede asumir mi generación y la anterior, y la anterior. Mi generación, y la siguiente y la siguiente.

A.S.: Un mito.

L.B.: Sí, eso es, un mito. (Blasco, 2017: 76)

De manera similar, sus obras se sirven de la Historia - especialmente la Historia del siglo XX - como medio para reflexionar sobre los conflictos del presente. En una entrevista realizada por Francisco Gutiérrez Carbajo para la antología Dramaturgas del siglo XXI, Blasco afirmaba 
que, en el teatro, los "hechos históricos suelen reflejarse como símbolos del afán de dar cuenta de la realidad concreta" (2014: 141). En efecto, en el teatro actual la dramatización de la Historia no tiene como fin "informar al público acerca de lo ocurrido en el pasado, sino, más bien, confrontar al público con ese pasado, un pasado que necesariamente tiene algo que decir a las sociedades del presente" (García-Manso, 2013: 41). En este sentido, también la Historia puede verse como un lenguaje común con el que tomar posiciones políticas.

El texto dramático de Fuegos (o el hígado de Prometeo) propone una exploración del tema del éxodo y la xenofobia a través de distintas escenas que dialogan con la tradición cultural y la historia. Aunque no existe una trama y se juega con diversos lenguajes expresivos, las escenas se conectan entre sí temáticamente y a través de la repetición de imágenes y referencias a los éxodos del presente y el pasado - el exilio republicano español, el Holocausto, la emigración de jóvenes españoles, la inmigración en España y los refugiados de la guerra de Siria-, la recurrencia de referencias mitológicas - el ave fénix, el mito de Prometeo-, y las referencias a la actualidad - noticias de prensa y fotografías de alto impacto, el racismo y la islamofobia, los mensajes de odio de figuras como Trump, etc. - Se repite en la obra la idea de la "reactualización" o retrofitting a la que se ve sometida la Historia, que, como le ocurre al ave fénix y al hígado de Prometeo, está condenada a repetirse de manera similar, aunque con nuevas técnicas generadas para el horror. Asimismo, se denuncia la progresiva insensibilización de la sociedad ante la violencia y la manipulación de la información en los medios de comunicación.

Como en otros textos dramáticos de Lola Blasco (Jódar Peinado, 2017: 120-122), destaca en Fuegos la dimensión metateatral, que se pone en evidencia desde la primera escena, donde se discurre sobre el carácter siniestro - en el sentido freudiano de lo unheimlich - del espacio donde la obra fue estrenada, la Cúpula del Milenio, y se hace referencia al grupo de jóvenes que la pone en escena - "Así que estamos aquí, / en La Plaza del Milenio... / en La Cúpula del Milenio... / un grupo de Millenials..." (Blasco, 2017: 21). La voz en primera persona de los jóvenes se manifiesta de manera constante en discursos que apelan directamente al público y hacen referencia al presente, sirviéndose para ello de lenguajes expresivos actuales. Por otro lado, el texto dramático aparece presentado en verso libre, con un predominio de repeticiones y estructuras sintácticas iterativas que contribuyen a dar una sonoridad poética a la palabra. A estos recursos se les suma, como ha analizado Checa Puerta, el "discurso paremiológico y la intertextualidad" (2012a: 14), que le otorgan un "carácter poético-conceptual" a un lenguaje dramático que, junto con las referencias a la tradición cultural, la Historia y el lenguaje coloquial juvenil asociado a las nuevas tecnologías, consigue "evocar variados tipos de resonancia" (ibidem 15). ${ }^{14}$

Para abordar estas temáticas relativas a la Historia y la realidad circundante, se recurre en Fuegos al testimonio y el documento. ${ }^{15} \mathrm{Tal}$ y como señala Peris Blanes, lo testimonial se asocia con textos y discursos no institucionalizados que denuncian o dan visibilidad a conflictos y acontecimientos históricos, vistos desde la perspectiva de las comunidades subalternas. En este sentido, lo testimonial tiene un componente político insoslayable:

No hay, desde luego, una definición totalmente satisfactoria de lo testimonial, pero el modo en que se ha usado en las últimas décadas permite localizar tres líneas de sentido básicas a las que ha sido asociado. En primer lugar, la representación de un acontecimiento o proceso violento (político o no) realmente ocurrido, del cual el texto desea dar cuenta y, en la mayoría de los casos, denunciar, hacer visible o construir su memoria. En segundo lugar, la presencia de una voz subjetiva que garantiza la veracidad de lo ocurrido, y que vincula la narración del acontecimiento con su circunstancia y su punto de vista. En tercer lugar,

${ }^{14}$ Por ejemplo, frases hechas como "la mierda esa del ojo por ojo" (Blasco, 2017: 20), "de aquellos fangos estos lodos" (53); y lemas popularizados a través de los medios de comunicación y las redes sociales: “iREFUGEES WELCOME!” (26), "haters gonna hate" (41).

${ }^{15}$ Ambos son recursos frecuentes en el teatro español actual, especialmente cuando se abordan temáticas históricas. Entre la cuantiosa bibliografía, cabe mencionar esfuerzos colectivos recientes como los de los volúmenes editados por Enrile (2016), Romera Castillo (2017) y el presente número monográfico de Revista de Escritoras Ibéricas.

UNED. REI, 7 (2019), pp. 209-236

ISSN 2340-9029 
la construcción de una versión diferente, cuando no opuesta, a las narrativas institucionales y oficiales sobre el pasado reciente. En ese sentido, muchos de los analistas culturales han vinculado la emergencia de la literatura testimonial a la búsqueda de canales nuevos de expresión para las comunidades subalternas. (Peris Blanes, 2014: 10-11)

Entre dichos analistas culturales, cabe citar a Beverley (2004: 2), quien considera el testimonio como el género literario de las comunidades oprimidas. Aquellas personas que habían sido tradicionalmente objeto del discurso, pero no sujeto (Spivak, 1988), se convierten en transmisoras de su propio testimonio. Esta es una característica relevante en lo que respecta al teatro comunitario, pues, como se ha señalado, es una modalidad proclive a fomentar la autorrepresentación y la agencia cultural de personas que no se dedican al teatro de forma profesional, pero cuyas vidas y experiencias se convierten en materia dramática y son interpretadas por ellas mismas. Así pues, podemos diferenciar la existencia de dos formas de testimonio en Fuegos. En primer lugar, se halla el testimonio como experiencia vital susceptible de ser transmitida oralmente. Este tipo de testimonio aparece representado en el capítulo III del texto dramático, a través del monólogo de Marah Rayan. El testimonio de Rayan cumple con las características principales del género testimonial. Aparece la voz subjetiva, una voz en primera persona que se presenta a sí misma, revela su identidad real e incide en su nombre, a modo de estribillo, en varios momentos del monólogo:

Perdón, perdón...

todavía no me he presentado,

me llamo Marah Rayan [...]. (Blasco, 2017: 58)

Me llamo Marah Rayan

y soy apátrida.

Nací en Jordania,

me crié en Siria,

y soy de origen palestino.

A mí me gusta decir que soy del mundo

solo que el mundo no lo sabe

o no quiere saberlo. (60)
Me llamo Marah Rayan

soy apátrida

y un águila me pica el hígado cada día,

como a Prometeo

pero este vuelve a crecer... (65)

Me llamo Marah Rayan

y soy apátrida. (66)

Este "yo" habla de un acontecimiento o proceso violento que desea visibilizar y denunciar. Cuenta su historia, que es también la historia de muchos otros, tal y como indica en la siguiente cita, e interpela de forma directa a un "vosotros" - el público lector/espectador- (Beverley, 2004: 1-2): "El conocimiento duele pero siempre es mejor / que el silencio. / Yo solo aspiro a contar mi historia. / La de mi familia. / La de mi pueblo. / Aspiro a iluminar, / a poner voz, / a todos aquellos que, / como yo, / se sintieron morir cada noche, / y cada mañana resucitaron" (Blasco, 2017: 66). Además, su testimonio adopta la dimensión transgresora que destaca Peris Blanes en su definición, al ofrecer "una versión diferente, cuando no opuesta, a las narrativas institucionales y oficiales sobre el pasado reciente" (2014: 11). De ahí que una parte del monólogo de Rayan se dirija a criticar estereotipos y prejuicios en torno a los refugiados vertidos en los medios de comunicación:

¡Musulmanes!

¡Terroristas!

¡Destrozan la economía!

Eso dicen de nosotros,

los medios de comunicación.

Los medios de comunicación son peores que las bombas,

los medios de comunicación

son las peores armas. (Blasco, 2017: 65)

En segundo lugar, el teatro $-\mathrm{y}$ especialmente el teatro comunitario- ofrece la posibilidad de corporeizar el testimonio a través de sus protagonistas, de transmitirlo a través de los propios sujetos de enunciación. El hecho de que sea la propia Rayan quien cuente su historia sobre 
el escenario, sin que medie la interpretación de un actor, la convierte en sujeto de su propia representación, al tiempo que le permite actuar contra las representaciones perversas que ofrecen los medios de comunicación sobre los refugiados. Aquí entra en juego lo que Cornago ha identificado como "actor testigo" al analizar el trabajo de autores contemporáneos como Angélica Liddell, que adoptan un tono confesional en sus obras: "el testigo es en primer lugar un cuerpo-confesión, lo que nos interesa es su pura presencia, el relato de vida escrito en su cuerpo, las marcas que ese pasado dejaron en su cuerpo" (2012: 59-60). En el caso del teatro comunitario, hay un testimonio que se desprende de la presencia escénica de los miembros de la comunidad, esos intérpretes no profesionales que no son sujetos habituales del discurso artístico. Su cuerpo es portador de información identitaria —edad, sexo, género, clase social, nacionalidad, etnia, religión, orientación sexual, etc. - En este sentido, llama la atención que en muchos montajes de teatro comunitario - como Fuegos o, por ejemplo, la adaptación de La casa de Bernarda Alba dirigida por Pepa Gamboa-, los intérpretes aparecen caracterizados con un vestuario que podría ser el mismo que llevan en su vida cotidiana. El público percibe a los miembros de la comunidad como tales y no solo como personajes dramáticos. En el caso de Fuegos, el público es capaz de identificar sobre la escena a los Navegantes - un grupo de jóvenes, en su mayoría estudiantes residentes en Valladolid-, acompañados de un grupo de Navegantes senior - mayores de 65 años, también residentes de la misma ciudad-, y de Marah Rayan, quien se identifica a sí misma como refugiada.

El documento, por su parte, aparece integrado en el espectáculo a través de la alusión a noticias de prensa recientes, fotografías de acontecimientos históricos e, incluso, declaraciones tristemente famosas de Donald Trump. Según la definición propuesta por Youker:

A document is a media object that is presented as a record of a fact or as a privileged representation of an absent person or a past event. A document is a representation that certifies for us that something happened [...] or that someone or something that is not currently present actually exists somewhere else. A document takes the place of actual people or events that cannot be apprehended directly by the senses. It certifies a particular account of the past, or it is authorized to represent the memory or the will of a specific person. (Youker, 2018: 2)

En este sentido, los documentos en una obra de teatro como Fuegos, todos ellos relacionados con los éxodos históricos, los movimientos migratorios del presente y la manera en que se tratan estos acontecimientos en los medios de comunicación, confrontan al público espectador con los hechos y lo invitan a reflexionar críticamente sobre ellos. En las escenas "Europa se sienta de espaldas" y "Pies de fotos para paisajes de cuerpos" (escenas II y III del capítulo I), que incluyen titulares de prensa y fotografías históricas, la concatenación de las diversas muestras documentales se realiza con el fin de provocar un impacto (est)ético en el público: en el primer caso, para mostrar la xenofobia y el racismo que impera en el tratamiento de las noticias sobre la inmigración y los refugiados y, en el segundo caso, para revelar los paralelismos siniestros que se producen entre pasado y presente y la repetición cíclica de la Historia. En ambos casos, sin embargo, el documento aparece insertado dentro de un discurso que modula la lectura que se debe hacer del mismo, como se puede observar en el siguiente fragmento de "Europa se sienta de espaldas":

"Las violaciones comenzaron mucho antes, en los albergues"

"Somos el mayor burdel de Múnich"

Dice un trabajador de Bayernkaserne,

una antigua base militar

reconvertida, ahora

en campo de refugiados.

"El mayor burdel de Múnich"

¿Por qué hablan de burdel y no de mafia?

¿Por qué tratan de negocio...

las agresiones?

Entonces, entiendo...

que si hay algo peor que ser mujer en este mundo...

eso es ser mujer, extranjera y pobre. (Blasco, 2017: 27-28)

Además de los intertextos documentales, se integran numerosas referencias culturales que pretenden lograr ese "lenguaje común" defendi- 
do por Lola Blasco. Entre ellas, destacan los mitos del ave fénix y Prometeo, con los que se simboliza la resiliencia de los refugiados, los migrantes e incluso los adolescentes, pero también el carácter cíclico de la Historia; la novela El corazón de las tinieblas, de Joseph Conrad;16 películas como El gran dictador (1940), de Charles Chaplin, ${ }^{17}$ Apocalypse Now (1979), de Francis Ford Coppola, basada en la novela de Conrad, y American History $X$ (1998), de Tony Kaye; ${ }^{18}$ y composiciones musicales como La cabalgata de las Walkirias, de Richard Wagner, mencionada por su utilización en la escena del bombardeo de Apocalypse Now. El uso de las referencias al ave fénix y Prometeo como hilo conductor a lo largo del drama cumple una de las funciones del mito en el teatro contemporáneo: "suscitar la reflexión y el planteamiento de una nueva visión sobre los hechos culturales y, en última instancia, sobre los políticos y sociales" (Vilches-de Frutos, 1983: 184). Ambos mitos se conectan con "el registro de lo ígneo" (Conte, 2017: 13), al que remite el título de la obra, y se van enlazando, a su vez, con otras referencias culturales "como si se tratara de una navegación en red, en un entramado intertextual que actúa como principio generador de la escritura" (14).

16 Tanto El corazón de las tinieblas, como Apocalypse Now y la famosa secuencia en la que suena La Cabalgata de las Walkirias aparecen en el monólogo de la escena IV del Capítulo I, en el que el protagonista habla sobre el miedo que sintió cuando se vio solo en un vagón de cercanías con un chico musulmán con "jellaba negra” y mochila que iba rezando (Blasco, 2017: 33): "Ninguno de los libros que he leído me quita el miedo, pienso... / las matanzas se perpetúan por las ideas de las naciones bien educadas... / pienso, / ¡El horror! ¡El horror! / Al fondo el fuego... el fuego... el fuego... / De fondo... Wagner" (ibidem: 35).

${ }^{17}$ La evocación de la película de Chaplin lleva a la protagonista de la escena I del capítulo II a imaginar "a Trump jugando con el globo, jugando... / hasta que lo pincha" (Blasco, 2017: 45).

${ }^{18}$ La referencia a American History $X$ aparece en la escena I del capítulo II ("El águila y la bandera"), cuando la protagonista de la escena se refiere a una de las secuencias más brutales de la película y narra la historia de su acercamiento y posterior distanciamiento de un grupo de neonazis. Se produce, por tanto, un interesante paralelismo entre la evolución psicológica de la joven de esta escena de Fuegos y la del protagonista de American History X, quien experimenta un proceso similar de concienciación.
En lo que respecta a los lenguajes expresivos, destaca la incorporación de códigos ligados a las redes sociales e internet, como el hashtag. ${ }^{19}$ En la ya mencionada escena III del capítulo I, titulada "Pies de fotos para paisajes de cuerpos" (Blasco, 2017: 31-32), se utilizan hashtags para calificar fotografías históricas de la Guerra Civil, el exilo republicano de 1939, la II Guerra Mundial, los campos de concentración, la guerra de Vietnam y la guerra de Siria, entre otros. El carácter telegráfico y esquemático de los hashtags, banal y frívolo, contrasta con el contenido grave de las imágenes. En algunos casos, se usan para describir objetivamente las imágenes, en otros, para invitar a realizar una lectura crítica y política de las imágenes, recurriendo en ocasiones al humor negro y lo grotesco. Por ejemplo, \#picoftheday, uno de los hashtags de uso más frecuente en las redes, se convierte en \#picofthedeath para calificar la fotografía "Muerte de un miliciano" de Robert Capa; mientras que, en una fotografía en la que soldados japoneses aparecen haciendo prácticas de tiro contra prisioneros aliados, se introduce el hashtag \#vintagephoto y \#deporte, generando un siniestro contraste. Además, el propio orden en el que suceden las imágenes traza paralelismos que invitan al espectador a reflexionar sobre las consecuencias de la violencia y el horror ayer y hoy, en España y en otros lugares del mundo, como se puede observar en los siguientes ejemplos:

HoMbres, MUJERES Y NIÑOS, APRESADOS TRAS UNA VALLA, SIN COMIDA Y SIN AGUA. ESCAPAN DE UNA DICTADURA.

\#Algeres1939 \#guerracivilespañola \#Francia

HOMBRES, MUJERES Y NIÑOS, APRESADOS TRAS UNA VALLA, SIN COMIDA Y SIN AGUA. ESCAPAN DE UNA DICTADURA.

\#Lesbos \#guerracivilsiria \#Grecia \# estápasando

$[\ldots]$

${ }^{19}$ El hashtag se usa en las redes sociales para crear palabras clave o etiquetas suscep-
tibles de identificar y agrupar distintos elementos en torno al tema o la idea conden-
sada en el hashtag. El hashtag aparece siempre precedido de una almohadilla y suele
estar conformado por una o varias palabras escritas sin espacios. Se usa con frecuen-
cia en plataformas como Twitter, Instagram o Facebook, tanto por parte de usuarios
como de empresas e instituciones. UNED. REI, 7 (2019), pp. 209-236

ISSN 2340-9029 
UN GRUPO DE PRISIONEROS ALEMANES ES OBLIGADO A VER IMÁGENES DEL HORROR DE LOS CAMPOS DE CONCENTRACIÓN NAZI. AlgunOS SE TAPAN LOS OJOS CON LAS MANOS. OTROS PRESTAN ATENCIÓN..

\#emoticonodelostresmonitos ${ }^{20}$

CUARENTA Y CINCO CEREBROS Y UN CORAZÓN CONSERVADOS en la fosa común de La Pedraja. Algunos todavía CON eI PROYECTIL DENTRO.

\#Burgos \#fosascomunes \#spainisdifferent \#españolesrepublicanos \#españolesporelmundo \#emoticonodelostresmonitos \#lasideasnomueren. (Blasco, 2017: 31-32)

El uso del hashtag en esta escena, como lenguaje expresivo con una finalidad crítica y una modulación irónica, resulta de gran originalidad y contrasta con otros usos de índole realista que se han podido ver en propuestas teatrales recientes, como el planteado por Nando López ya desde el título de su obra dramática \#malditos16 (2017), en la que se aborda el tema del suicidio adolescente y la importancia de la comunicación como medida preventiva. En conexión también con el lenguaje coloquial juvenil se halla la frase "haters gonna hate", muy vinculada al uso de las redes sociales, que se repite en la escena I del capítulo II a modo de estribillo.

Otro lenguaje expresivo actual utilizado en Fuegos es el rap, que, como ya fue mencionado, configura el "Poem(a) dolescente" compuesto por el Navegante Lorenzo Asensio (capítulo II, escena II). Dicho "poema para rapsodia" (Blasco, 2017: 55) alude a algunos de los referentes de la obra, como el mito del Prometeo y el ave fénix, y encadena imágenes asociadas al fuego y la combustión, que conectan con el momento liminal, de transición, que supone la adolescencia. El rap es, además, una forma musical que Lola Blasco había explorado en obras previas como Pieza paisaje en un prólogo y un acto y En defensa (Un concierto de despedida). Como ana-

20 \# emoticonodelostresmonitos se refiere a tres emoticonos que representan los rostros de tres monos, uno se tapa los ojos, otro se tapa los oídos, y el tercero se tapa la boca. Representan el proverbio: "no veas lo malvado, no escuches lo malvado, no digas con maldad" (Miralles, 2017). En la obra, esta idea se manifiesta en varios momentos de forma crítica, como llamada a la responsabilidad civil. liza Checa Puerta, en el rap "prevalecen la primera persona, la feroz crítica del parresiastés y la estructura circular del ditirambo griego" (2012b: 363), unas características que la propia Blasco declara haber tenido en mente en sus propuestas dramáticas:

Si convertí al coro en un coro de rap fue porque me pareció que era equivalente. Yo pensé en el coro griego, y en cómo cantaba las injusticias de su época y me pregunté, ¿quién hace eso hoy día? $Y$ la respuesta fue: el rapero. No en vano la palabra rap proviene de rapsoda. El rapero es el poeta de la calle, del pueblo, un poeta que canta las injusticias contemporáneas que todos conocemos. El rapero no descubre nada nuevo, simplemente enuncia lo que todos sienten para compartir el dolor. Y así fue cómo el rap o el spoken word empezaron a aparecer dentro de mis obras, casi como testimonio del desastre, emulando el "Yo lo vi" de Goya. (Blasco, 2016: 47)

Como es sabido, una de las funciones principales del coro trágico consistía en expresar los sentimientos del público, es decir, de la comunidad (Vernant/ Vidal-Naquet, 1987: 26-27). En consonancia con esto, en el montaje de la obra hubo textos declamados por Los Navegantes a modo de coro - como la escena I del capítulo I, en la que una voz en off mecanizada, actuando como un despersonalizado corifeo, era replicada por todos los intérpretes en escena, mientras se movían por el escenario- o en las que dos actrices pronunciaban el mismo texto, la segunda de ellas a modo de eco - como ocurría en la escena I del capítulo II, "Odio por odio" - . Estos aspectos del montaje, unidos al hecho de que los Navegantes se hallan en todo momento presentes en la escena, contribuyen a potenciar la dimensión colectiva, comunitaria, de la propuesta escénica.

\section{Conclusiones}

El teatro comunitario permite a sus practicantes convertirse en sujetos del discurso artístico y, como defiende Erven, expresar sus preocupaciones de forma colectiva y democrática, con el apoyo de profesionales de la escena. Un buen ejemplo de esta dinámica se halla en "La Nave" del 
Teatro Calderón, un proyecto dirigido por Nina Reglero y Carlos Nuevo para jóvenes de 16 a 26 años con inquietudes artísticas diversas que trabajan a lo largo de la temporada para generar un montaje escénico multidisciplinar. En el caso de Fuegos (2017), los Navegantes llevaron a cabo una investigación en torno a los éxodos, trabajando en grupos en propuestas que partían de distintas disciplinas artísticas, con el apoyo de profesionales como Nina Reglero (dirección escénica), Carlos Nuevo (espacio escénico, composición plástica y audiovisual), Manuela Barrero (coreografía) y Ana Garay (vestuario). Para la creación del texto dramático, contaron con la dramaturgia de Lola Blasco, quien escribió la obra teniendo en cuenta las inquietudes de los Navegantes e incorporando textos e ideas generados por ellos.

En la puesta en escena y el texto dramático, confluyen una serie de elementos - testimonio, documento, intertextos culturales y nuevos lenguajes expresivos- que instan al público a reflexionar críticamente sobre los éxodos históricos, las migraciones actuales y el miedo y odio al diferente que se transmite a través de los medios de comunicación. El espectáculo, como suele ocurrir con el teatro comunitario, pone en juego diversas formas de testimonio. En primer lugar, se incorpora el testimonio como experiencia vital a través del monólogo de Marah Rayan, joven refugiada de origen palestino que vivió parte de su vida en Siria y abandonó el país por la guerra y, que, además, es la encargada de transmitir su relato sobre la escena, fomentando así su autorrepresentación y subjetividad. En segundo lugar, la propia presencia de los distintos miembros de la comunidad en el escenario constituye una forma de testimonio. El público puede percibir a los intérpretes como sujetos agentes de su propio discurso artístico y como miembros de una comunidad, pues los Navegantes son la base del montaje y participan en todos los estadios del proceso creativo. En resumidas cuentas, a través de "La Nave" del Teatro Calderón de Valladolid no solo se está acercando el teatro a los jóvenes, sino que también se está acercando a los jóvenes al resto de la comunidad.

\section{Recibido: 05/06/2019}

\section{Aceptado: $14 / 10 / 2019$}

UNED. REI, 7 (2019), pp. 209-236

\section{Referencias bibliográficas}

Abuín González, Anxo (2016), "Historia oral, memoria colectiva y comunidad en el teatro del mundo: el caso de teatro verbatim", Signa, 25, pp. 273-296.

"Aves Migratorias de Madrid" (2018), Conde Duque, <https://www. condeduquemadrid.es/labs/aves-migratorias-de-madrid $>$ [consulta: 26/02/2019]

Beverly, John (2004), Testimonio. On the Politics of Truth, Minneapolis / London: U. of Minnesota Press.

Blasco, Lola (2016), "Sentido de los códigos musicales en la actualización del teatro político", en José Romera Castillo (ed.), Teatro y música en los inicios del siglo XXI, Madrid: Verbum, pp. 41-59.

--- (2017), Fuegos... (O el hígado de Prometeo). / En defensa... (Un concierto de despedida), Vigo: Ediciones Invasoras.

Checa Puerta, Julio E. (2012a), "Prólogo", en Lola Blasco, Proyecto Milgram, Madrid: CDN, pp. 7-22.

--- (2012b), "Dramaturgas españolas del siglo XXI: Lola Blasco (1983), del ditirambo al rap", en Francisca Vilches-de Frutos y Pilar Nieva-de la Paz (eds.), Imágenes femeninas en la literatura española y las artes escénicas (siglos XX y XXI), Philadelphia: Society of Spanish and Spanish-American Studies, pp. 353-367.

--- (2017), "Conciertos de despedida: dramaturgas españolas frente al exilio juvenil", en Catherine Flepp y Marie-Soledad Rodriguez (eds.), Créations au féminin. Les dramaturges espagnoles d'aujourd'hui, Paris: L'Harmattan, pp. 141-157.

Cohen-Cruz, Jan (2005): Local Acts. Community-Based Performance in the United States, New Brunswick / New Jersey / London: Rutgers University Press.

Conte, David (2017), "Anábasis: Lola Blasco y las metáforas de la resistencia”, en Lola Blasco, Fuegos... (O el hígado de Prometeo). / En defensa... (Un concierto de despedida), Vigo: Ediciones Invasoras, pp. 7-16.

UNED. REI, 7 (2019), pp. 209-236

ISSN 2340-9029 
Cornago, Óscar (2012), "Alegorías de la actuación: el actor como testigo", Acotaciones, 28, pp. 55-74.

“El Proyecto artístico de 'La Nave' despega en el Calderón” (2014), Europa Press, 11 octubre, <https://www.europapress.es/castilla-y-leon/noticiaproyecto-artistico-nave-despega-calderon-valladolid-45-jovenes-buscandar-forma-talento-20141011123049.html> [consulta: 26/02/2019].

Enrile, Juan Pedro, ed. (2016), El teatro documento. Acotaciones, 37.

Erven, Eugene van (2000), Community theatre. Global perspectives, London / New York: Routledge.

--- (2015a), “The Tension between Community and Art", RIDE: The Journal of Applied Theatre and Performance, 20.3, pp. 407-410.

--- prol., (2015b), “Artes escénicas y comunidad”, Abierto al Público. Artes Escénicas e Inclusión Social, 4, pp. 46-75 < https://www.redescena.net/descargas/proyectos/abiertoalpublico2015.pdf > [consulta: 26/02/2019].

García-Manso, Luisa (2013), Género, identidad y drama histórico escrito por mujeres en España (1975-2010), Oviedo: KRK.

--- (2018), “Teatro y diversidad: propuestas escénicas por la autorrepresentación y el empoderamiento", en Susanne Hartwig (ed.), Diversidad cultural-ficcional-¿moral?, Madrid / Frankfurt am Main: Iberoamericana / Vervuert, pp. 263-279.

García Pindado, Sandra (2017a), Estudio de una propuesta de artes escénicas en el entramado del Teatro Calderón de Valladolid: La Nave 2016-2017 [Trabajo Fin de Máster], Valladolid: Universidad <http://uvadoc.uva.es/ handle/10324/25239> [consulta: 26/02/2019].

--- (2017b), "Una travesía en La Nave" [documental grabado entre noviembre de 2016 y mayo de 2017], Youtube, 13 julio, <https://www.youtube.com/watch?v=4Fc8S63XqnU> [consulta: 26/02/2019].

Geer, Richard Owen (1993), "Of the People, By the People and For the People: The Field of Community Performance", High Performance, 16.4, pp. 28-31. madrid.es/labs/generacion-global> [consulta: 26/02/2019].

"Green-Eyed Monster. Un espectáculo de La Nave a partir de Otelo de William Shakespeare" [dossier de prensa] (2006), La Nave, <http://lanave. tcalderon.com/index.php/green-eyed-monster/> [consulta: 26/02/2019].

Gutiérrez Carbajo, Francisco (2014), Dramaturgas del siglo XXI. Madrid: Cátedra.

Jódar Peinado, Pilar (2017), “En defensa y Canícula, de Lola Blasco: la revolución hecha teatro", Feminismo/s, 30, pp. 111-128.

Lambright, Anne (2013), "Dead Body Politics: Grupo Cultural Yuyachkani at Perú's Truth Commission”, en Florian N. Becker, Paola S. Hernández y Brenda Werth (eds.), Imagining Human Rights in Twenty-First-Century Theater. Global Perspectives, New York: Palgrave Macmillan, pp. 27-44.

"La Nave lleva al Calderón Ágora, un proyecto que habla de muros y gira sobre la deconstrucción hacia el contacto" (2018), La Vanguardia, 6 junio, <https://www.lavanguardia.com/local/castilla-leon/20180606/444151918441/la-nave-lleva-al-calderon-agora-unproyecto-que-habla-de-muros-y-gira-sobre-la-deconstruccion-hacia-elcontacto.html>.

Miralles, Francesc (2017), "La enseñanza de los tres monos", El País Semanal, 26 marzo, <https://elpais.com/elpais/2017/03/26/ eps/1490483155_149048.html> [consulta: 26/02/2019].

Motos, Tomás (2015), "Modalidades del teatro aplicado", en Tomás Motos y Domingo Ferrandis (eds.), Teatro aplicado. Teatro del oprimido, teatro playback, dramaterapia, Barcelona: Octaedro, pp. 35-65.

Ojeda, Alberto (2018), "Cambiar el teatro para cambiar la realidad", El Cultural, 23 marzo, <https://www.elcultural.com/revista/escenarios/Cambiarel-teatro-para-cambiar-la-realidad/40828> [consulta: 26/02/2019].

Pérez Rasilla, Eduardo (2012), "Notas sobre la dramaturgia emergente en España”, Don Galán, 2, <http://teatro.es/contenidos/donGalan/donGalanNum2/pagina.php?vol=2\&doc=1_6> [consulta: 26/02/2019]. 
Peris Blanes, Jaume (2014), "Literatura y testimonio: un debate", Puentes de Crítica Literaria y Cultural, 1, pp. 10-17.

Prentki, Tim y Sheila Preston (2009), "Applied Theatre. An introduction”, en Tim Prentki y Sheila Preston (eds.), The Applied Theatre Reader, London / New York: Routledge, pp. 9-15.

Romera Castillo, José, ed. (2014), Creadores jóvenes en el ámbito teatral $(20+13=33)$, Madrid: Verbum.

--- ed. (2017), El teatro como documento artístico, histórico y cultural en los inicios del siglo XXI, Madrid: Verbum.

Sastre, Alfonso (2002), Diálogo para un teatro vertebral, Alfonso Sastre / Eva Forest, <http://www.sastre-forest.com/sastre/pdf/dialogopara.pdf > [consulta: 24/09/2019].

Spivak, Gayatri Chakravorty (1988), “Can the Subaltern Speak?”, en C. Nelson y L. Grossberg (comp.), Marxism and the Interpretation of Culture, Basingstoke: Macmillan Education, pp. 271-313.

TEVEO Asociación (2017), "Nina Reglero y Carlos Nuevo en los Encuentros Te Veo 2017" [vídeo], Youtube, 24 noviembre, <https://www.youtube. com/watch?v=irS2-POJZLc $>$ [consulta: 26/02/2019].

Vernant, Jean-Pierre y Pierre Vidal-Naquet (1987), Mito y tragedia en la Grecia Antigua. I. Madrid: Taurus.

Vidales, Raquel (2017), "Y los jóvenes fueron al teatro", El País, 25 mayo, $<$ https://elpais.com/cultura/2017/05/24/actualidad/1495629688_996965. html> [consulta: 26/02/2019].

Vilches-de Frutos, Francisca (1983), "Introducción al estudio de la recreación de los mitos literarios en el teatro de la postguerra española", Segismundo, 17. 37-38, pp. 183-209.

Youker, Timothy (2018), Documentary Vanguards in Modern Theatre, London / New York: Routledge. 